\title{
TELEVISÃO, MUNDO DA VIDA E MOBILIDADE SIMBÓLICA: AFAVELAE SEUS MORADORES NA VISÃO DE ADOLESCENTES $^{1}$
}

\author{
Simone Maria Rocha
}

\begin{abstract}
RESUMO
O objetivo deste artigo é discutir sobre o conceito de mundo da vida, relacionando-o à hipótese da mobilidade simbólica com base em uma análise da recepção e discussão da série televisiva Cidade dos Homens (Rede Globo, 2002), feita em grupos focais com adolescentes moradores e não-moradores de favela de Belo Horizonte e do Rio de Janeiro. Consideramos grupos focais não apenas uma metodologia qualitativa de pesquisa, mas uma mediação capaz de incentivar a produção de sentido em situaçães de recepção coletiva e evidenciar processos de questionamento de representações, formação e sustentação de identidades. Nossa hipótese é que, embora as representações exibidas nos media reflitam uma tendência à reprodução de estereótipos, podemos, ainda assim, verificar uma relativa pluralidade nesse ambiente e identificar produções com a explícita intenção de modificar tais estereótipos. Sendo assim, os media representariam uma importante mediação, cuja capacidade de filtrar, mediatizar e enfatizar determinados temas oferece perspectivas, modela imagens e incita a criação de contextos políticos e sociais de interação e debate. Dada a presença significativa dos media na vida social, é nosso propósito mostrar como a televisão e suas mensagens, que tanto colaboram para a cristalização de um estoque de conhecimento, podem contribuir, também, para a problematização e deslocamento de entendimentos previamente formulados.
\end{abstract}

PALAVRAS-CHAVE: mundo da vida; mobilidade simbólica; televisão; adolescentes; favela.

\section{INTRODUÇÃO}

Embora saibamos que as representações exibidas nos media reflitam uma tendência à reprodução de estereótipos, não podemos deixar de evidenciar que há uma relativa pluralidade nesse ambiente e identificar produções com a explícita intenção de modificar tais estereótipos. Assim, torna-se possível indagar acerca da contribuição que essas produções podem dar às reflexões em relação ao conhecimento do outro e ao reconhecimento de uma possível mobilidade simbólica em relação aos grupos excluídos. Consideramos exclusão social como um problema de natureza moral, político e social que leva a uma desvalorização simbólica de determinados grupos (DEMO, 2002; OLIVEIRA, 1997; ZALUAR, 1997; 2004).

\footnotetext{
1 Agradeço a Ângela Marques e Rousiley Maia pelas valiosas sugestões e ao Conselho Nacional de Desenvolvimento Científico e Tecnológico (CNPq) pela concessão de apoio financeiro que tem contribuído para a realização de nossa pesquisa.
}

$\mathrm{O}$ que acontece quando surgem produtos midiáticos que pretendem desconstruir imagens estereotipadas? Será que eles conseguem desestabilizar configurações já dadas? As pessoas conseguem notar a proposta de um novo padrão de visibilidade dos grupos excluídos?

Nas últimas décadas, muitos pesquisadores (BLUMLER \& GUREVITCH, 2000; DALGHREN, 1993; NORRIS, 2000; MAIA, 2004; THOMPSON, 1998) vêm evidenciando que parte significativa das relações que os sujeitos estabelecem com o mundo em que vivem - para além de suas interações face a face - tem se realizado através dos media. Sendo assim, eles representam uma importante mediação cuja capacidade de filtrar, mediatizar e enfatizar determinados temas oferece perspectivas, modela imagens e incita a criação de contextos políticos e sociais de interação e debate.

Diante de tal fenômeno, nosso propósito aqui seria o de pensar como esse espaço de visibilidade midiática interage de modo significativo com os demais espaços, fornecendo material e recursos 
simbólicos que constroem tanto as experiências diretas quanto as indiretas dos indivíduos. Nessa medida, propomo-nos a pensar tal interação a partir do conceito de mundo da vida (segundo as concepções trabalhadas por A. Schutz e J. Habermas) e da tentativa de relacioná-lo à hipótese da mobilidade simbólica. Buscaremos evidenciar como nossos conhecimentos prévios, e que muitas vezes são sedimentados pelas mensagens recebidas dos media, podem ser problematizados a partir de representações e discursos construídos por esses mesmos meios, desde que apresentem uma proposta que escape aos estereótipos comumente veiculados. Em outras palavras, o que queremos evidenciar é o modo pelo qual a televisão e suas mensagens colaboram tanto para a cristalização quanto para o questionamento de aspectos desse estoque de conhecimentos. Não apenas a televisão, mas, também, o contexto reflexivo de recepção é fundamental na medida em que é nele que os sentidos são reconstruídos e problematizados.

Para viabilizar nossa proposta, escolhemos como grupos focais os quatro primeiros episódios $^{2}$ da minissérie Cidade dos Homens (Rede Globo, 2002). Essa série é uma narrativa ficcional que aborda a vida de dois adolescentes, sua vida na favela e os problemas enfrentados, como a violência, a carência material, a falência do ensino público, o preconceito social e racial, entre outros. No nosso entendimento, esse programa mostra o morador de favela de outro modo, ou seja, de um modo mais complexo, que escapa a associações mecânicas que ligam violência e criminalidade à favela, sem levar em conta quaisquer outros elementos. Cidade dos Homens possibilita uma outra maneira de pensar, pois cria um novo padrão de visibilidade que põe em primeiro plano a cotidianidade, os dilemas do dia-a-dia, a luta diante das dificuldades e as preocupações de sujeitos comuns, que levam vidas

2 Para o escopo de nossa análise, optamos por trabalhar somente com os quatro primeiros episódios da série, que foram: 1) A coroa do Imperador; 2) O cunhado do cara; 3) O correio; e 4) Uólace e João Vítor. Tal escolha se justifica pelo fato de que, nesse primeiro ano, a montagem dos episódios ainda não tinha sido totalmente submetida ao "padrão Globo de qualidade" e ambienta suas histórias de modo mais relacionado à vida das comunidades. Os demais episódios dos anos subseqüentes apresentavam temáticas tais como gravidez na adolescência, uma visita ao presidente da república, para cobrar mais ações políticas na área social etc., ou seja, ampliaram para outras dimensões que não cabiam na discussão aqui proposta. também comuns ${ }^{3}$. Na fala de um de seus realizadores, tal série tinha um propósito alternativo em relação ao que vem sendo veiculado. Segundo George Moura, "Quando Cidade dos Homens chegou à TV a idéia era fazer uma espécie de 'anti' Cidade de Deus ${ }^{4}$, ou seja, revelar que na favela existem os dramas cotidianos, que não obrigatoriamente se resumem ao problema da violência gerado pelo tráfico de drogas. Cidade dos Homens, durante esses anos todos, mostrou isso, ao fazer uma crônica da vida privada dos seus personagens principais" (MOURA, 2005).

3 Essa parece ser a "leitura preferencial" dos codificadores desse programa: despertar para o fato de que há humanidade nesses lugares, pessoas comuns e vida em comunidade, crianças e sua ingenuidade e não apenas a "lei do tráfico", a violência e a criminalidade. Estamos nos referindo aqui a uma das leituras típico-ideais propostas por Stuart Hall (2003) em seu texto "Codificação/decodificação", quando esse autor trata do processo de codificação de mensagens televisivas e suas possibilidades de construção de significados (leituras) a serem feitas pelo telespectador. Além da leitura preferencial, aquela cuja interpretação estará de comum acordo com os objetivos do codificador, o autor aponta a leitura negociada e a leitura oposicional.

4 Longa-metragem exibido em 2001, Cidade de Deus se passa em um único cenário: o conjunto habitacional de Cidade de Deus, zona oeste do Rio de Janeiro. A história é dividida em três partes. A primeira, situada no fim dos anos 1960, mostra os primeiros anos de existência desse conjunto habitacional, para onde se mudam duas crianças, Buscapé e Dadinho. Buscapé tem 11 anos; seu irmão Marreco forma, com os amigos Cabeleira e Alicate, um grupo de bandidos conhecido como Trio Ternura, cuja especialidade é assaltar os caminhões de gás. Dadinho acompanha esse grupo de marginais e sonha ser como eles. Buscapé, por sua vez, não gosta de ter irmão bandido. Quer um futuro diferente para sua vida. A segunda parte do filme se passa nos anos 1970. Buscapé continua seus estudos e arruma um emprego num supermercado. Enquanto isso, Dadinho torna-se um pequeno líder de gangue com grandes ambições: quer se tornar traficante. Em pouco tempo, Dadinho tornase o bandido mais perigoso e temido do local, recebe um novo apelido, Zé Pequeno, e expande seu negócio. A terceira parte, situada no começo dos anos 1980, mostra como Zé Pequeno se transforma em um dos traficantes mais poderosos do Rio de Janeiro, protegido por um exército armado de crianças e adolescentes entre 11 e 18 anos, até que ele cruza o caminho de um trocador de ônibus conhecido como Mané Galinha. Depois de ver sua mulher ser estuprada, Mané Galinha decide se vingar de Zé Pequeno, associandose a outro traficante local, Sandro Cenoura. Estoura a guerra na Cidade de Deus. Nesse meio tempo, Buscapé, que sempre sonhou ser fotógrafo, consegue sua primeira máquina profissional. Registrar essa guerra será a grande chance de sua vida (VIRTUALBOOKS, s/d). 


\section{O PERCURSO METODOLÓGICO: GRUPO FOCAL COMO MEDIAÇÃO}

Nossa opção pelo grupo focal foi feita na medida em que o consideramos não apenas como uma metodologia qualitativa de pesquisa, mas como uma mediação capaz de incentivar a produção de sentido em situações de recepção coletiva e evidenciar processos políticos de questionamento de representações, formação e sustentação de identidades, reconhecimento, legitimidade e inserção das questões levantadas por grupos marginalizados na esfera pública ${ }^{5}$. Ou seja, não nos interessa apenas passar um trecho de um programa televisivo e ouvir as opiniões dos participantes a respeito do que acabaram de ver, mas, sim, ressaltar as ocasiões sociais em que as suas habilidades críticas emergem no momento em que se encontram reunidos para trocar experiências e argumentos acerca de um determinado tema ou assunto. "O grupo focal não é um agregado conveniente de opiniões individuais, mas uma simulação desses contextos comunicativos rotineiros, mas relativamente inacessíveis que nos ajudam a descobrir os processos através dos quais o sentido é socialmente construído através da fala cotidiana" (LUNT \& LIVINGSTONE, 1996, p. 85)

Por isso, acreditamos que seja proveitoso usar o grupo focal para encorajar as pessoas a se engajarem umas com as outras e a expressarem verbalmente suas visões de mundo. Nesse sentido, em algumas circunstâncias do debate, o papel do moderador pode aparecer de modo mais contundente, visando justamente àquele encorajamento. Ao adotarmos o grupo focal nessa perspectiva, acreditamos estar vinculando-o a uma certa concepção da política enquanto atividade cotidiana de construção coletiva dos significados e sentidos sociais que regem as relações entre sujeitos que, reflexivamente, trocam pontos de vista, de modo a buscar entender o outro, a própria condição e seu lugar no mundo.

As escolhas metodológicas que guiaram esta pesquisa estruturam-se do seguinte modo: como Cidade dos Homens era uma narrativa construída a partir da visão de seus protagonistas, os adolescentes Acerola e Laranjinha, procuramos adolescentes para participar da pesquisa. Em seguida, segundo nosso propósito, procuramos jovens que

5 Sobre grupo focal, ver Morgan (1997) e Lunt e Livingstone (1996). já pertenciam a grupos de convivência nas comunidades, pois nosso pressuposto era o de que tais grupos os auxiliavam na construção de sua visão de mundo e evitavam a "construção" de grupos especificamente para a realização do grupo focal. $\mathrm{E}$, por último, pretendíamos analisar em que medida aquela série, que claramente fazia referência aos morros do Rio de Janeiro, seria interpretada por um público, também morador de favela, mas de Belo Horizonte. Nossa indagação era a seguinte: aquela representação poderia ser generalizável para outros contextos? Os grupos realizados com moradores de favela foram organizados do seguinte modo: primeiramente, fizemos o contato com dois grupos: o ECO, no Morro Santa Marta, local onde foi filmada boa parte do primeiro ano da série, e o núcleo Agente Jovem - que é fruto da parceria de organizações não-governamentais (ONGs) com a Prefeitura de Belo Horizonte, que objetiva oferecer uma alternativa aos adolescentes no período em que não estão na escola - na região da Barragem Santa Lúcia, em Belo Horizonte $^{6}$. Em ambos os grupos, os adolescentes têm entre 15 e 18 anos. A dinâmica constava de exibição do programa, seguida da discussão orientada pelo roteiro semi-estruturado dividido em três eixos: i) o morro e a televisão; ii) os moradores de favela na televisão e iii) é possível uma mobilidade simbólica que suspenda dicotomias como morro versus asfalto? Foram realizados dois grupos focais em cada favela: em Belo Horizonte, eles contaram com aproximadamente dez participantes cada, e, no Rio de Janeiro, variaram entre três e seis participantes. O registro das opiniões e considerações dos adolescentes se deu principalmente de três modos: gravação das discussões realizadas, depoimentos individuais e registro por escrito, que, no caso do primeiro grupo realizado em Belo Horizonte, a maioria preferiu fazer.

Já o grupo realizado com os não-moradores de favela aconteceu com nove adolescentes, todos com 15 anos, estudantes do primeiro ano do Ensino Médio, de um colégio particular na zona

\footnotetext{
6 Nossos encontros iniciais se deram nos meses de agosto e setembro de 2005, nos quais apenas participamos das reuniões dos respectivos grupos, bem como visitamos algumas casas, participamos de eventos culturais para, oportunamente, expor o motivo de nossa presença. Depois desses contatos, passamos, nos meses de outubro, novembro e dezembro de 2005 , a realizar efetivamente os grupos focais.
} 
sul de Belo Horizonte, uma região com moradores de alto poder aquisitivo, e contou com os mesmos procedimentos acima referidos. Nossa indagação, nesse caso, era a seguinte: este grupo percebe alguma diferença na abordagem feita em Cidade dos Homens? Para ele, há ou não estigmatização e qual seria o seu modo de lidar com a diferença ${ }^{7}$ ? A escolha desse grupo se deu em virtude do nosso interesse em saber como adolescentes de uma condição socioeconômica distinta acionam seu conhecimento de fundo para interpretar essa série. Optamos por realizar a discussão com estudantes de uma escola pelo fato de ser esse um espaço de convivência entre eles, o que já possibilita a construção comum de conhecimentos prévios.

\section{MUNDO DA VIDA E MOBILIDADE SIM- BÓLICA}

Todos nós, no curso de nossa vida diária, deparamo-nos com situações que demandam um esforço interpretativo que norteie nossas ações e nosso entendimento do mundo. $\mathrm{O}$ conjunto de experiências cotidianas, o estoque de conhecimentos que temos à mão, os valores e normas nos quais fomos socializados e dos quais lançamos mão para subsidiarem nossa interpretação, é o que autores como Alfred Schutz (1979) e Jurgen Habermas (1998) denominaram mundo da vida. Para Schutz, “o 'mundo da vida cotidiana' significará o mundo intersubjetivo que existia muito antes do nosso nascimento, vivenciado e interpretado por outros, nossos predecessores, como um mundo organizado. Ele agora se dá à nossa experiência e interpretação. Toda interpretação desse mundo se baseia num

\footnotetext{
${ }^{7}$ Vale ressaltar que coube à autora deste artigo o papel de moderadora dos grupos focais. Nesta oportunidade, gostaria de agradecer às instituições e pessoas que colaboraram de forma efetiva na realização desta pesquisa, tais como: 0 Movimento Viva Rio, o Grupo ECO (RJ), o Projeto Agente Jovem Núcleo Barragem Santa Lúcia (PBH), Pedro Strozemberg, Itamar, Flaviana, Lucas, Márcia Maria, Fátima, bem como aos adolescentes que se dispuseram a participar das discussões e debates realizados. Para o grupo focal realizado no Colégio da zona sul de Belo Horizonte, a cooperação da bolsista de Iniciação Científica/UFMG Débora Santos no contato com os adolescentes, no apoio logístico e na negociação com a direção do Colégio foi de fundamental importância. Ainda nesse grupo focal, coube ao também bolsista de Iniciação Científica/UFMG Augusto Veloso Leão o papel de observador do grupo. Suas anotações foram preciosas e muito me auxiliaram na transcrição das fitas do modo mais fiel possível.
}

estoque de experiências anteriores a ele, às nossas próprias experiências e àquelas que nos são transmitidas por nossos pais e professores, as quais, na forma de 'conhecimento à mão', funcionam como um código de referência" (SCHUTZ, 1979, p. 72; grifos no original).

Podemos, assim, entender que o mundo da vida nos é dado de antemão pela tradição e pelo trabalho de construção cognitiva dos que aqui estiveram antes de nós. Contudo, o mundo da vida é também o mundo da ação cotidiana, um mundo que se transforma quando aparece uma situação que exige uma problematização de conhecimentos até então consolidados. Isso porque "o mundo da vida cotidiana é a cena e também o objeto de nossas ações e interações [...] Assim, trabalhamos e operamos não só dentro do, mas também sobre o mundo" (idem, p. 73). Por isso, é preciso entendê-lo sempre de modo a considerá-lo dentro de um fluxo permanente e mutável de acordo com a situação à qual se enfrenta e que demanda diferentes aspectos desse "mundo" na abordagem de uma determinada questão. Mas isso nem sempre ocorre de modo coerente e homogêneo, totalmente claro e livre de contradições. Se pensarmos que são os interesses dos indivíduos ${ }^{8}$ que atuam na definição do que eles querem conhecer melhor, que as situações mudam de tempos em tempos, que nem sempre esses indivíduos estão tão engajados em saber de fato sobre algo, reconheceremos as inúmeras possibilidades de estruturação do estoque de conhecimento. Ainda de acordo com Schutz, "O homem, na vida diária [...] tem, a qualquer momento, um estoque de conhecimento à mão que lhe serve como um código de interpretações de suas experiências passadas e presentes, e também determina sua antecipação das coisas que virão. Esse estoque de conhecimento tem sua história particular. Foi constituído de e por atividades anteriores de experiência de nossa consciência, cujo resultado tornouse agora uma posse nossa, habitual [...]. Por outro lado, esse estoque de conhecimento à mão não é nada homogêneo [...]" (idem, p. 74). Desse modo, seriam nossas experiências, envolvimento e interesse numa determinada questão que nos aju-

\footnotetext{
8 Sabemos que os interesses nem sempre são predefinidos, mas, sim, são definidos no curso das interações. No sentido aqui exposto, queremos nos referir àquilo que desperta nossa atenção, que nos diz algo significativo e que, portanto, varia de indivíduo para indivíduo.
} 
dariam a acionar e estruturar o tipo de conhecimento que iremos adotar na sua solução ${ }^{9}$.

J. Habermas também entende o mundo da vida como um tipo de conhecimento relativamente préreflexivo, o qual os indivíduos tomam como se fosse conhecimento de fundo, que lhes oferece alguma estabilidade, pois, para que ele venha à tona, algo precisa ser tematizado, algum novo sentido precisa ser produzido por meio das relações interpessoais. Para Habermas, "o mundo da vida é estruturado por tradições culturais e ordens institucionais assim como pelas identidades que se originam dos processos de socialização. Por esta razão, o mundo da vida não se constitui em uma organização à qual os indivíduos pertencem como membros, nem como uma associação na qual os indivíduos se encontram, nem um coletivo composto por participantes individuais. Ao invés disso, práticas comunicativas cotidianas, nas quais o mundo da vida está centrado, são nutridas pelos modos de interação da reprodução cultural, da integração social e da socialização. Tais práticas estão, por sua vez, enraizadas nesses modos de interação" (HABERMAS, 1998, p. 251; grifos no original).

Esses apontamentos teóricos acerca da reflexão sobre o mundo da vida em Schutz e Habermas levam-nos a acreditar que este conceito, tal como desenvolvido pelos autores, explora as experiências diretas.

No que concerne à análise que pretendemos neste artigo, o ponto a ser enfatizado diz respeito à relação entre o estoque de conhecimento que forma o mundo da vida e as mensagens produzidas pelos media, em particular pela televisão. Sendo assim, e considerando que os autores refletem apenas sobre as experiências diretas, um desafio se configura, pois nossa proposta é pensar como aquelas representações veiculadas nos media, que intencionalmente buscam quebrar certezas já cristalizadas, podem atuar sobre esse mundo da vida

\footnotetext{
9 A isso, Schutz denomina de relevâncias e nos esclarece: “[...] É o problema em particular do qual nos ocupamos que subdivide nosso estoque de conhecimento à mão em zonas diferentes de relevância para a sua solução e estabelece, assim, os limites das várias zonas do nosso conhecimento mencionadas acima, ou seja, zonas de nitidez e de vagueza, de clareza e obscuridade, de precisão e ambigüidade" (SCHUTZ, 1979, p. 74)
}

e promover um tipo de deslocamento chamado por nós de mobilidade simbólica.

Consideramos mobilidade simbólica ${ }^{10}$ uma noção que traduz um possível deslocamento dos sentidos produzidos pelos sujeitos que rompe com uma visão preconceituosa acerca de excluídos, e possibilita uma visão que os toma como sujeitos comuns, moral e politicamente iguais, com dilemas e aspirações também comuns. É importante ressaltar que tratamos essa "mobilidade" como uma hipótese, pois sabemos que tal possibilidade ocorre em meio a disputas de poder, a lutas contra posições hegemônicas, muitas vezes engendradas por ordens do discurso - conceito abordado segundo a acepção de M. Foucault (2001) cuja formação contribui para estabelecer o que é "verdade" e o que é "válido" sobre as coisas, pessoas, grupos e eventos que fazem parte de uma realidade social. No caso do presente estudo, poderíamos fazer referência aos discursos hegemônicos que circulam sobre as favelas e seus moradores, e as várias tentativas de contraposição e superação desses discursos. Isso porque nosso pressuposto é o de que, no caso dos moradores de favela, o imaginário social dominante brasileiro interpreta o "favelado" como um tipo social homogêneo e a favela como lugar de ausência e caos social ${ }^{11}$. Nesse sentido, torna-se importante para nós investigar se, através dos media e de suas mensagens, é possível identificar a provocação de uma mobilidade simbólica dessa visão de que a favela seria apenas um lugar de ausência e de excluídos, para uma perspectiva em que ela seria um lugar no qual os sujeitos estabelecem interações

10 Sabemos que se trata de uma profícua reflexão nas Ciências Sociais acerca dessa disputa simbólica. O que gostaríamos de acrescentar à discussão diz respeito à contribuição que os media podem oferecer nessa negociação de sentidos.

11 A favela é quase sempre definida pelo que ela não teria: um lugar sem infra-estrutura urbana - água, luz, esgoto, coleta de lixo -, sem ruas pavimentadas e bem delimitadas, globalmente miserável, sem ordem, sem lei, sem regras, sem moral, enfim, o lugar da carência, do vazio, do perigo. Muitos autores (ZALUAR, 1985; 1997; 2004; ALVITO, 2003; RINALDI, 2003; ZALUAR \& ALVITO, 2003) já apontaram para essa questão da estigmatização e rotulação sofrida por esses indivíduos moradores de favela. Há, para esses autores, uma espécie de imaginário preconceituoso, alimentado tanto por aqueles que não querem ser associados à favela quanto pelo poder público, como ainda pelos que lá não moram. 
sociais, possuem aspirações de vida, moralidades que dão sentido e alimentam seus sentimentos de pertença a uma comunidade, embora saibamos que muitas vezes esses mesmos media não contribuem para essa "mobilidade".

A seção seguinte traz fragmentos das discussões obtidas nos grupos de modo a evidenciar em que medida se dá essa relação entre conhecimento de fundo, interação e recepção televisiva. Tais fragmentos intercalam as discussões dos grupos de adolescentes moradores e não moradores de favela.

\section{MUNDO DA VIDA, INTERAÇÃO E RECEP- ÇÃO TELEVISIVA: AS FALAS DOS ADO- LESCENTES}

Nossa proposta de investigar a relação que os sujeitos estabelecem entre aspectos de seu conhecimento de fundo e a recepção televisiva nos aponta para dois níveis de interpretação que muitas vezes se interceptam: o primeiro seria aquele no qual os atores mobilizam um conhecimento de fundo compartilhado e construído por experiências concretas; e o segundo nível seria aquele no qual os atores acionam um conhecimento partilhado e construído pelos media e por suas representações. Isso pode ser percebido nos tipos de interpretação que cada um dos grupos fez da série. Vejamos o que disseram esses adolescentes ${ }^{12}$ :

"Felipe: Eu acho que eles viviam uma grande dúvida. Eles não sabem se eles querem estudar mesmo ou se eles querem ser traficantes.

Moderadora: Eu gostaria que vocês recuperassem em qual momento do programa se fez alguma menção de que um dia eles tiveram a dúvida de querer ser traficante ou outra coisa.

\section{Renata, Eduarda e Erica: Nenhum.}

Moderadora: Então, será que vocês não estão trazendo algumas noções que já estavam na imaginação de cada um e que, a todo momento, elas vêm na nossa cabeça e acabam direcionando o nosso olhar?

Luiza: É claro que sim. A gente já vem com aquela idéia de favela.

Paula: Mas é difícil se livrar disso. A gente

12 Optamos por trocar os nomes dos participantes dos grupos a fim de preservar sua identidade. escuta, vê o tempo todo que é assim, não vai ser de uma hora para outra que a gente consegue mudar.

Moderadora: Deixem-me fazer uma proposta: vamos nos esforçar para voltar para Cidade dos Homens. É claro que nós não conseguimos esquecer o que já pensamos, mas vamos nos esforçar para repensar o que entendemos por morador de favela a partir disso que a gente está vendo agora.

Joana: Mas, mesmo esse programa mostra a relação com o tráfico, mostra pessoas novas com armas, menino morrendo.

Luiza: A tendência deles é virar traficante.

Paula: Muitos justificam isso para dar uma vida melhor para a mãe que trabalhou para criar eles. $\mathrm{E}$ agora eles querem recompensar. Tanto que no Falcão ${ }^{13}$ todos diziam "um dia, eu vou sair dessa vida". Só que eles morrem antes.

Moderadora: Mas, vamos voltar para Cidade dos Homens. Vocês acham que são essas informações que a gente recebe para dar essa leitura que vocês estão fazendo?

\section{Renata: Não.}

\section{$[\ldots]$}

Felipe: Eu acho que a gente vai pensar no que for passado pra gente. Se passarem que lá eles se matam, a gente vai acreditar que eles se matam. Só agora a gente sabe que, apesar de lá ter traficante, armas, assassinato, lá é também uma comunidade unida.

13 O documentário Falcão, meninos do tráfico, foi ao ar no dia 19 de março de 2006 no programa Fantástico, da Rede Globo de Televisão, com duração de 90 minutos. Trata-se de uma narrativa cujo objetivo, segundo seus realizadores, entre eles o rapper MV Bill, era o de despertar o interesse da sociedade, das autoridades e das instituições para o grave problema social que atinge crianças e adolescentes moradores das favelas - o envolvimento cada vez mais precoce com o tráfico de drogas. O documentário chama a atenção por vários motivos, dentre eles: 1) serem as crianças e adolescentes os depoentes e narradores de suas próprias vidas, de seus problemas e de seu envolvimento com o tráfico; 2) ter sido feito por um morador da favela, o rapper MV Bill, que entra nos barracos, filma aquilo que está "acontecendo" naquele momento e apresenta a questão como se esse documentário pudesse ser lido como a "Verdade", a "Realidade" da vida nas favelas. 
Paula: A gente sabe pouco que tem projetos lá, essas coisas assim. Que a favela é uma comunidade. A maior parte da informação que a gente tem é de violência, então a gente cria uma imagem de violência" (Grupo focal, Colégio, Belo Horizonte).

Esse trecho do debate mostra o quanto, apesar de estarem diante de uma representação que se pretende diferente daquela corrente, eles recorrem a conhecimentos anteriores e de alguma maneira cristalizados para emitir suas opiniões.

No que diz respeito àqueles que moram na favela, as críticas à série foram contundentes, pois, embora esses adolescentes identifiquem sim, aspectos de sua realidade, enfatizam, contudo, que a representação é unilateral, posto que não aborda a pluralidade de vivências na favela, como pudemos constatar no seguinte momento da discussão:

"Paulo: Não me surpreende, pois o que mostra no filme para mim já é uma realidade. Me surpreenderia se mostrasse outra coisa porque, assim, o que mostrou no filme é uma realidade em termos, foi, no caso, só coisas negativas a respeito da favela, de uma comunidade. O tempo todo passou tiroteio, parece até que o Morro vive constantemente em guerras, entendeu? E isso não é verdade, a gente também tem muitas coisas boas que acontecem dentro da comunidade. Do jeito que foi colocado no filme, daqui a pouco a gente vai ter que comprar um guarda-chuva blindado, porque vai ser chuva de bala direto. [...] Sinceramente, se fosse, se a idéia-base fosse aproximar a favela e o pessoal do asfalto, na minha opinião, eu acho que eles fizeram um péssimo trabalho. Porque não foi bom. Se fosse para aproximar... você vê, teve tiroteio, o pessoal na rua para poder assaltar. Então, a pessoa pensa: 'É isso o que o pessoal da favela faz? É isso?' Aí começam a criticar.

Lili: Eu acho que realmente eles pecaram porque não mostraram tanto as coisas boas da favela. Só que eles falaram que mostraram, por exemplo, quando aparece o garoto indo pra escola, a relação ali, mas é pouquíssimo. Isso aí é muito pouco. [...] Exageraram o outro lado. Então, acabou ficando uma imagem de que favela só tem marginal, que a criança tem contato com a criminalidade muito cedo" (Grupo focal, Morro Santa Marta, Rio de Janeiro)

Se concordamos com o fato de que, contemporaneamente, cada vez mais nos engajamos num novo tipo de interação, o que significa que o nosso conhecimento e contato com o outro se dá de maneira crescente por meio dos media (LIVINGSTONE, 1998; THOMPSON, 1998), podemos afirmar que as narrativas e representações mediáticas são fundamentais para compor o estoque de conhecimento sobre os locais, as pluralidades etc. Em muitos momentos, a fala dos adolescentes não-moradores de favela, quando diziam algo sobre os moradores, era subsidiada de modo perceptível por esse conhecimento previamente formulado que eles vêm acumulando por meio de suas experiências indiretas construídas, sobretudo, pelos meios. Afirmavam saber sobre o outro e isto era claramente feito a partir dos estereótipos. Contudo, essa foi uma relação controvertida, posto que aspectos dos mundos da vida eram acionados e assumiam diferentes relevâncias no processo interpretativo de cada um. E isso pode ser captado nos dois grupos, ou seja, dos que moram e dos que não moram na favela. Entre os que moram:

"Moderadora: Será que vocês já não estão com um 'pé atrás' e por isso têm dificuldade de reconhecer Cidade dos Homens como uma representação diferente, se nós observamos, por exemplo, que no último episódio - Uólace e João Vítor não se fez nenhuma referência ao tráfico?

Lucas: Isso que eu ia falar agora. Isso já é automático. A pessoa já procura uma coisa para identificar aquilo que ela vive cotidianamente, entendeu? Se ela não encontra, ela tenta de alguma maneira mostrar isso de qualquer jeito. $E$ isso mostra o quê? Mostra que a gente não está acostumado a ver um programa, ver uma minissérie, ver alguma coisa na televisão tentando mostrar nossa realidade. Porque assim, Cidade dos Homens está tentando representar ainda muito pouco, tem muita coisa que deve ser mostrada, mas está tentando. Assim, está tentando mostrar, mas mesmo assim a gente tem muita resistência, sabe? O pessoal vê as coisas, igual eu tô vendo o Carlos falar, e tenta buscar alguma coisa que justifica ele falar só sobre essa questão da violência.

Mara: Mas, mesmo assim, teria que ter mais espaço na mídia, né? Porque você vê que o programa é de temporada em temporada, a hora que é, dificilmente dá para muitas pessoas assistir.

Lucas: Eu acho que é mais um estigma mesmo. A pessoa de tanto viver aquilo, ela procura de 
certa maneira, acho que tenta se encontrar naquela situação mostrada" (Grupo focal, Barragem Santa Lúcia, Belo Horizonte).

Por sua vez, entre os que não moram na favela, esse conhecimento de fundo muitas vezes obscurecia ou dificultava algum entendimento novo daquela situação analisada:

"Felipe: Nas comunidades também, os chefões lá são vistos mais como justiceiros, porque tudo o que acontece quem resolve são eles. Eles são a base das favelas. Eles mantêm a calma, o controle das favelas.

Luiza: Dentro da favela é a lei deles. Vivem como se fosse em outra cidade.

\section{Luiza: Eles mandam.}

Moderadora: Mas, seria possível ver isto através desse programa, Luiza?

Luiza: Eu acho porque, na cidade do alto (alto do morro) tinha gangue dando tiro no meio da rua.

\section{Felipe: Lutando por território..}

Luiza: E aqui alguém vai impedir eles de fazerem isso, se eles fizessem isso no meio da rua. $\mathrm{Na}$ favela, ninguém tem o poder de impedir eles de fazerem, porque eles mandam, mas aqui tem a polícia" (Grupo focal, Colégio, Belo Horizonte).

Como dissemos anteriormente, os mundos da vida não são homogêneos, coerentes nem tampouco imutáveis. É preciso estarmos atentos para os momentos em que fragmentos que compõem nosso pano de fundo são questionados, problematizados de modo concreto e essa problematização termina por demandar dos indivíduos uma nova interpretação do que está sendo tematizado. Nesse caso, foram significativas as falas dos adolescentes que não moram na favela no intuito de ver, em Cidade dos Homens, alguma coisa desse outro que escapasse do modo pelo qual ele é comumente estereotipado.

"Eduarda: Eu acho que o programa mostra o lado positivo da favela, a solidariedade deles, eles tentando se ajudar, a amizade. Mostra que na favela nem todo mundo é bandido, que é cada um por si lá dentro. O programa mostra que é diferente.

Luiza: Mostra a união, eles são unidos... Entre eles, eles são unidos. Eles têm grupos contra. Mas, entre eles tem solidariedade.
Felipe: É mesmo. A gente vê que eles têm solidariedade, que eles são mais amigos.

Paula: Mostra que lá não tem assalto.

Luiza: Ele [Acerola] mesmo falou que lá dentro não tinha assalto" (Grupo focal, Colégio, Belo Horizonte).

As opiniões, entretanto, não eram o tempo todo coerentes. Houve controvérsias entre eles e até mesmo contradições em relação ao que havia sido dito anteriormente. Nesse embate de opiniões, muitas vezes alguns insistiam no seu argumento como melhor, solicitando, inclusive, que o colega repensasse a sua opinião a partir do que ele expunha. Portanto, ao mesmo tempo em que se dispunham a interpretar Cidade dos Homens sob essa outra ótica, sempre retornavam àquilo que o seu mundo da vida informava sobre os moradores de favela. Nesses momentos, cabia à moderadora uma interferência um tanto mais contundente, no sentido de problematizar falas tão arraigadas.

"Moderadora: O que Cidade dos Homens poderia oferecer de diferente, para que vocês refaçam suas opiniões? Vocês viram, por exemplo, que as expectativas, as opiniões, as aspirações de Uólace e João Vítor se aproximavam em alguns momentos...

Eduarda: Eu acho que mostra o lado positivo sim. Vocês não lembram daquela hora em que o Acerola está vendendo CD e depois ele faz as contas de quantos ele tem que vender para comprar o tênis? Então, sabe, está mostrando que ele trabalha, que ele tenta fazer uma coisa digna para ver se ele consegue melhorar a vida dele. Eu acho que o objetivo de Cidade dos Homens é realmente mostrar que não é todo mundo que quer entrar para o tráfico. Eu acho que o objetivo deles foi mostrar o lado positivo, o lado do cotidiano.

Felipe: Eu também acho. Foi mostrar que tem alguma alternativa.

Luiza: Eu não concordo. Eu acho que é um outro mundo completamente diferente do nosso. Isso de vender $C D$ é o que dá para ele ser.

Moderadora: Quando vocês os vêem com a mesma vontade de consumir o hambúrguer, por exemplo, de ter o mesmo tênis, você acha que ainda assim são mundos completamente diferentes?

Luiza: Não são mundos, mas são realidades diferentes. 
Ruth: Mas, gente, nós temos que pensar que a gente tem valores que eles não têm. Tipo que a gente consegue, como eu explico? A gente tem, sei lá, mais noção, a gente sabe que a gente estudando, a gente vai conquistar.

\section{Felipe: A gente tem mais informação.}

Luiza: E isso é mostrado através dos meninos, do João Vítor e do amigo riquinho dele, que eles podem conseguir isso, que, se eles estudarem, tirarem nota boa, podem ser alguém na vida. Já o Acerola e o Laranjinha, eles não vêem a escola como um meio de chegar a ser alguém, de conseguir. Eles têm diferentes modos de interpretar a escola. Os dois grupos de estudantes das diferentes classes sociais vêem a escola de jeitos totalmente diferentes.

Joana: É diferente, porque assim 6,50 pra gente não é nada, um hambúrguer pra gente tem muito menos valor do que pra eles. Pra eles é tipo uma raridade.

Felipe: Mas eu acho que o programa mostra a realidade. Dá uma fugida de mostrar só a violência e mostra esse outro lado.

Érica: Eu acho que aprofundou mais na vida cotidiana" (Grupo focal, Colégio, Belo Horizonte).

A discussão acima transcrita nos faz perceber o quanto os fragmentos do mundo da vida podem ser de alguma forma questionados, quando os indivíduos são chamados a falar sobre uma questão que passa a ser tematizada pelos media de outra forma. Nosso argumento é o de que representações como essas podem, sim, atuar sobre mundos da vida diferenciados e contribuir para uma mobilidade simbólica. Contudo, bem sabemos que essa não é tarefa fácil, nem imediata. Se o estoque de conhecimento nos é dado também pelas tradições, por nossos predecessores, e também pelo material simbólico fornecido pelos media, que vem sedimentando esse conhecimento, é de se supor que uma mudança no nível interpretativo represente um desafio aos conhecimentos de fundo. É o que podemos perceber nos argumentos dos adolescentes do Colégio em relação ao fato de intepretarem programas, como a referida série, como uma oportunidade de ver o outro, que não se conhece diretamente, de uma maneira diferente:

"Felipe: Eu acho que diminui muito a discriminação em relação a eles.
Paula: Mas, se vocês pensarem nisso que a gente está vendo aqui, aprofundou um pouco, mas ainda é muito pequeno, se a gente pensar. A gente só vai conhecer mesmo quando a gente for lá.

\section{$[\ldots]$}

Ruth: Tem que pensar também que a gente vem vendo isso desde quando a gente nasceu. Não é uma coisa assim: viu um programa, muda sua cabeça de uma hora pra outra.

Luiza: Porque isso é verdade. Não se pode mudar totalmente a mentalidade. Não é $100 \%$ dos pivetes que não têm a intenção de roubar. Muitos deles têm a intenção de roubar. Eu acho que nem tem que mudar a mentalidade, tem que diminuir. Mudar totalmente não.

Felipe: Eu acho que vai demorar muito para mudar o pensamento. Acho que nem nossos filhos vão ainda saber como lidar" (Grupo focal, Colégio, Belo Horizonte).

Um outro exemplo disso foi a recusa dos adolescentes moradores de favela de enxergar, em $\mathrm{Ci}$ dade dos Homens, uma proposta diferente do discurso hegemônico acerca desse grupo. O que queremos dizer é que os mundos da vida dos realizadores, dos moradores da favela e dos adolescentes de classe média, ainda que possam ter seus sentidos negociados, desencontraram-se, porque o conhecimento de fundo mobilizado para entender aquela situação representada envolveu experiências que se chocam. Daí o entendimento, por parte dos realizadores, de que mostrar a favela de um modo diferente seja expor mães preocupadas com a educação de seus filhos, para que eles não se tornem marginais, e crianças freqüentando a escola.

E, por outro lado, por parte dos moradores, houvesse uma recusa de reconhecer isso como o "lado positivo" da favela. Diante da pergunta, se a série, ao mostrar alguma coisa diferente da violência, por exemplo, os garotos indo para a escola, preocupados com a avó, a amizade entre eles, não estaria propondo uma outra representação da favela e de seus moradores, os adolescentes manifestaram seu desacordo, ou seja, para eles, essa não é uma abordagem que mostra o "lado positivo da favela":

"Marcos: Se minha mãe estiver passando mal, é claro que eu vou me preocupar com ela.

Isabele: Eu não acho que esse tipo de preocupação demonstra o lado positivo da favela. Eu acho 
que não. Porque, se você pegar qualquer criminoso que tá aqui, lógico que se preocupa com a mãe. Do mesmo jeito que uma pessoa normal se preocupa com a mãe. Não acho que existe um lado positivo específico da favela.

Vera: Até quando você falou da amizade entre o Acerola e Laranjinha, que o Laranjinha deu o dinheiro para o outro, mesmo assim, a amizade levou o Laranjinha a fazer uma coisa ruim, que foi na boca do tráfico pedir dinheiro.

Lili: O problema é que, da maneira que eles mostram, a impressão que dá é que a maioria do morro é assim, mas não é isso, sabe? É a minoria, entendeu?

Paulo: Até o lado bom, o lado que poderia ser bom, foi uma coisa meio... O seguinte: na escola, mostrava eles na escola, mas você viu que não mostrou em momento nenhum eles assistindo a uma aula decente.

\section{Lili: Sempre tumultuada.}

Paulo: Tumultuada, bolinha de papel, o que a professora falava não dava certo.

Lili: A professora nem respondia o que eles perguntavam.

Paulo: Professora histérica, gritando. Isso pode ser até realidade para algumas pessoas, mas [...] não é só porque mora na favela que se torna um favelado" (Grupo focal, Morro Santa Marta, Rio de Janeiro).

Importante mencionar que esses adolescentes reconhecem a violência, o crime, a pobreza como presentes em suas vidas. Mas contra-argumentam essa realidade com a idéia de que favela não é só isso e insistem nessa crítica ao programa. Constroem um discurso no qual o principal argumento é o de que precisam ser reconsiderados pelos demais, a partir de outro prisma. E essa é a luta que enfrentam para construir essa identidade de maneira diferente, ou seja, demandam que os media ampliem seus discursos de modo que possam ser vistos como atores sociais moralmente capazes e iguais politicamente a todos e que deixem de representar a favela apenas como um lugar violento:

"Lili: Todo dia, toda hora. Quem vê isso pensa: 'Pô, na favela não é mole não. Caramba, nem estudar o moleque pode'.

Paulo: É. O que mostrou no filme é o que acontece. Mas ele só mostra o lado negativo da favela.

Carol: Se mostrasse o lado positivo seria até legal, porque só mostra a criminalidade, como se fosse o dia-a-dia. Não passou os projetos que tem na favela, a família, a união, que nem sempre é muita, mas também tem" (Grupo focal, Morro Santa Marta, Rio de Janeiro)

Essa "mobilidade", no entanto, só pode ser analisada e captada nas interações que os sujeitos travam com o mundo e com os outros. E essas interações foram claramente reivindicadas tanto pelos moradores quanto pelos não-moradores envolvendo a situação da co-presença, mas também uma representação mais negociada por parte dos media da complexa vida nas comunidades. Entre os que não moram na favela, esse diálogo mostrou uma disposição de entrar em contato, construir uma experiência direta com o outro, como podemos ver por meio da discussão:

"Luiza: De todo modo, nossa visão é superficial, porque a gente não tem muito contato. E se a mídia só transmite a violência, a gente só tem conhecimento da violência e não é só isso que acontece.

Joana: Mas não adianta só conhecer pela televisão. Eu acho que tem que haver algum tipo de interação para isso acabar.

Ruth: Mas é o primeiro passo e pode até ajudar.

Felipe: Tinha que ter mais programas como esse para conscientizar de que a favela não é só um lugar perigoso, mas que tem pessoas com vida normal.

Moderadora: Mas, Joana, o que você chama de formas de interação?

Joana: O negócio da interação é assim, a partir do momento em que eles têm projeto, isso precisa ser mostrado.

Felipe: Eu acho que a gente, do asfalto, vai pra lá só pra fazer documentário. A gente não passa o interesse para eles de uma convivência amigável. Eles pensam que a gente só tem interesse, assim, como se eles fossem tipo uma experiência, que a gente só quisesse ver, analisar, observar...

Luiza: Depois, tchau!

Felipe: É. Depois, tchau. Não [se] preocupa 
com eles" (Grupo focal, Colégio, Belo Horizonte).

Assim, pudemos perceber que, embora os grupos tenham procedido de modos distintos no que diz respeito à interpretação da série, acreditamos que seria possível pensar na capacidade dos media em colaborar na promoção de uma mobilidade simbólica, por meio do debate que eles suscitam, como nos foi revelado pelas interações discursivas construídas nos grupos focais. Contudo, é preciso ter cautela sobre esse poder da mídia de contribuir para essa "mobilidade", ao questionar essas representações estereotipadas. $\mathrm{O}$ que queremos dizer é que não compartilhamos de uma visão ingênua sobre o funcionamento e os modos operatórios dos media, ou seja, temos clareza de que trabalham com interesses, rotinas de produção e enquadramento de temas numa encruzilhada de disputas institucionais, comerciais, políticas etc., nem pensamos ser a cena midiática um espaço franqueado, livre de quaisquer constrangimentos. Bem sabemos que esse caminho de acesso aos media é tortuoso, com diversas barreiras e dificuldades.

Contudo, a dificuldade não está só na promoção dessa "mobilidade" entre esses mundos da vida indiretos e mediados. Há também dificuldade em aproximar os mundos da vida onde ocorrem as experiências concretas dos moradores de favela e dos demais grupos da sociedade. Foi o que alegou o grupo de adolescentes do Colégio de Belo Horizonte:

"Felipe: eu acho que programas como esse possibilitam uma aproximação entre morro e asfalto.

Ruth: É. Esse é o primeiro passo. Você conhecer pra depois interagir. A televisão não resolve. Ela mostra e dá vontade na gente de ir lá conhecer.

Felipe: Por isso a gente precisa de mais informação. Quem vai [se] aproximar de uma coisa que você sabe que vai ser assaltado? Acho que tem que ter muita informação desse tipo e diminuir o documentário igual Falcão. Qualquer pessoa fica chocada pensando que jovens da nossa idade estão morrendo. $\mathrm{O}$ que sobreviveu só sobreviveu porque estava preso.

\section{$[\ldots]$}

Moderadora: Vocês disseram que programas como esse tendem a ser uma janela, mas por si só não vão conseguir mudar. Se houvesse mais pro- gramas, vocês acham que pensariam diferente?

Érica: Pensar eu acho que a gente vai, mas agir é que é difícil.

Luiza: É como a Ruth falou, tem uma cultura onde a gente nasceu, a gente já está acostumado a ver desse jeito.

Joana: Eu acho que muda o jeito de pensar sim, mas a prática é muito difícil. Eu ainda vou ter medo se encontrar um grupo de favelado na rua. É difícil" (Grupo focal, Colégio, Belo Horizonte).

Quando perguntamos o que pensavam acerca da violência no morro, a partir do que viram na série, o debate ocorrido entre os adolescentes moradores da favela de Belo Horizonte chamounos a atenção. Isso porque esses participantes procuraram expressar que os episódios mostram uma realidade que lhes causa estranhamento, justamente porque ainda atrelavam-na a uma representação que não pode ser generalizada, uma vez que permanece ligada ao que o senso comum designa como "a favela carioca":

"Carlos: Bom, aqui é menos, aqui é diferente, aqui é menos perigoso do que lá. Eu estou falando menos perigoso assim, menos violento. Lá o tráfico é mais pesado do que aqui. Não tem como falar que não é.

Moderador: Vocês acham que lá o tráfico está mais presente...

Ana: As gangues são mais perigosas. Igual, por exemplo, aqui também tem gangues rivais que nem igual o Morro e lá embaixo, mas não são tanto assim não. Não pode nem passar, atravessar, tem gente que mora lá embaixo e não pode subir aqui em cima. Aqui não tem o comando que tem lá, na boca...

Mara: Mas, eu discordo de vocês dois, porque o que a gente tá vendo é o que a mídia tá mostrando, a gente não foi lá, não conviveu um dia lá, para saber como é que é lá. A gente vê aqui o que passa na televisão, entendeu?

Carlos: uma coisa que eu queria falar, porque eu não consegui concluir. A realidade é aquela como tá lá. Lógico, que nem você falou, que lá não é tudo aquilo. Mas, vamos convir que tem um pouquinho daquilo sim. É lógico que tem seu lado beneficente, tem o Criança Esperança, projetos... 
Ana: É. Um tráfico mais violento com certeza é. Não tem nem comparação Cidade dos Homens com aqui. Que nem eu falei que são gangues rivais pior do que aqui na Barragem, no Morro, aqui na favela. Nossa Senhora! Se eu morasse num lugar igual a esse dali, eu mudava. Igual, por exemplo, na Rocinha, no Rio de Janeiro, é aquela realidade mesmo. Porque na Rocinha tem que ter permissão pra tudo, pra entrar, pra sair, até polícia tem que ter permissão pra entrar lá. Toda vez que entra polícia lá pra trocar tiro com os bandidos, ou morre a polícia ou morrem os bandidos" (Grupo focal, Barragem Santa Lúcia, Belo Horizonte).

É importante destacar esta que nos parece ser uma questão inusitada: os próprios moradores de favela de Belo Horizonte falam sobre a condição dos moradores de favela do Rio pela mediação da televisão. Tal processo os levou a reproduzir o mesmo discurso elaborado pelos adolescentes do Colégio, ou seja, viam "a favela do Rio" como um lugar de extrema violência, criminalidade e sob constante controle do tráfico. Sendo assim, como poderíamos nos surpreender diante da interpretação dos adolescentes de classe média, que têm um mundo da vida distinto, se aqueles que têm uma condição de vida semelhante reproduzem o mesmo discurso?

\section{CONCLUSÃO}

Se quem está na "favela de Belo Horizonte" faz uma idéia de quem está na "favela do Rio" semelhante àqueles que possuem outras referências, este nos parece ser um aspecto relevante, uma vez que nos aponta para a presença significativa dos media na composição de mundos da vida construídos pelas experiências indiretas. Por viverem uma condição semelhante aos moradores de favela do Rio de Janeiro, poderíamos esperar que os meninos de Belo Horizonte interpretassem de um modo mais negociado aquilo que recebiam pela televisão. Contudo, esses adolescentes, justamente por serem aqueles que vivem em situação semelhante, não fizeram distinções que fossem satisfatórias. De modo muito tímido, procuraram relativizar, destruir a visão homogênea e fazer questionamentos. Não negociaram sua interpretação com um padrão de visibilidade que pretendia ser diferente e isso os levou a dizer quase o mesmo que os adolescentes do colégio particular.

Podemos perceber, diante dos debates travados, o quanto o mundo da vida guia a interpretação, o enquadramento construído em cada gru- po, independente de o produto ser aquele que tinha como propósito um padrão de visibilidade diferenciado em relação ao comumente veiculado. Isso porque este enquadramento está ligado aos sentidos dados, previamente formulados, que já vêm sendo sedimentados ao longo da história de vida de cada um desses adolescentes.

Ao mesmo tempo, é preciso considerar, de modo cada vez mais sério, a demanda apresentada pelos moradores por uma representação que de fato aborde outros elementos da vida na favela. É preciso mudar a forma da produção e inovar no que diz respeito aos padrões de visibilidade e enquadramento desse grupo. Acreditamos que, se esse universo for mostrado de forma mais negociada, sem fugir de sua complexidade e de seus dilemas, mas também evidenciando a solidariedade e o comum ali existente, os públicos poderão ver que a favela é plural, rica e que, se ela tem muitos problemas, várias poderão ser as soluções alternativas.

Particularmente, movimentos sociais e ONGs vêm tendo maior conscientização da importância da mobilização política para que uma ação coletiva seja bem-sucedida. É comum porta-vozes desses movimentos acusarem os discursos hegemônicos dos media de focar apenas na violência e no que a favela tem de pior. Segundo alguns membros dessas organizações, os media não se preocupam em mostrar de modo adequado as ações comunitárias, a vida em comum levada por pessoas comuns.

Iniciativas como as do grupo Afro-Reggae da Favela de Vigário Geral do Rio de Janeiro, da ONG Nós do Cinema $(\mathrm{RJ})^{14}$, dos vários grupos que cons-

14 Esse exemplo nos parece significativo, pois trata-se de uma ONG que foi formada após as filmagens do longa Cidade de Deus, que contou com elenco composto por jovens de comunidades de baixa renda. A "Nós do Cinema" possui vários projetos, entre eles cursos profissionalizantes e experiência prática em cinema. Os jovens participam de produções próprias e estagiam em grandes filmes. Um dos projetos desenvolvidos é o "Juntando Gente": "O objetivo desse projeto é reduzir o preconceito social entre diferentes classes sociais". Filmes como Cidade de Deus e o seriado Cidade dos Homens e outras produções são utilizados como estímulo para repensar a realidade das favelas e como esses espaços são retratados pela imprensa e indústria do entretenimento. A partir disso os participantes discutem mitos, preconceitos e estereótipos relacionados ao universo das favelas cariocas e da população. Essa iniciativa tem 
troem os sites na internet ${ }^{15}$, além de muitos outros movimentos - como o liderado pelo rapper MV Bill - cada vez mais procuram ocupar o espaço dos media para se fazerem presentes e parte integrante da sociedade, falando por si mesmos e reconhecendo os problemas com os quais convivem, mas procurando mostrar que nas favelas não existem apenas a violência, a criminalidade e o tráfico de drogas como única fonte de sobrevivência econômica. Muitas dessas iniciativas procuram enfatizar a construção cultural e política desses lugares, as alternativas de vida ali existentes (como os cursos pré-universitários, as diversas oficinas e cursos profissionalizantes e várias outras lutas empreendidas junto ao poder público), contribuindo para revigorar o processo de formação dessa identidade coletiva do modo como julgam mais adequado. São formas que conferem voz a esses sujeitos que sempre foram excluídos ou submetidos a toda forma de desrespeito. Embora saibamos que essa questão dos possíveis deslocamentos de sentidos produzidos pela percepção de ações coletivas seja relevante, ela não é o objetivo central deste artigo, posto que tal reflexão demandaria outros aspectos a serem discutidos, tais como o dilema entre a identidade individual e a identidade coletiva dos moradores de favelas.

E, por fim, apesar do fato de que, embora a mobilidade simbólica não tenha acontecido neces-

contribuído para promover o diálogo entre "o morro e o asfalto" (NÓS DO CINEMA, 2006).

15 Como exemplo, podemos citar o portal Ocupar Espaços, uma iniciativa de várias favelas de Belo Horizonte. Segundo informação retirada do portal, "O projeto está sariamente, no caso aqui em questão, gostaríamos de evidenciar o processo que começa a ser gestado, o "colocar em marcha" de um possível deslocamento e de uma desestabilização daquelas certezas básicas às quais esses sujeitos recorrem para lidar com o outro. E temos a convicção de que o grupo focal oportunizou justamente isso, ou seja, permitiu a instauração de questionamentos que puderam ser feitos nas instâncias cotidianas de convivência dos sujeitos - como a escola e os grupos da comunidade - e que, de algum modo, os levou a repensar e, aos poucos, quem sabe, a redefinir o que pensam acerca desse outro, como nos disse a adolescente: "Érica: Agora que a gente parou para conversar sim. Porque, muitas vezes, quando eu assistia, eu não percebia e nem pensava em nada disso que a gente está falando agora".

Não podemos negligenciar o fato de que os meios estão inseridos em âmbitos sociais, culturais, distintos e complexos, e que a interpretação que os sujeitos fazem daquilo que recebem está ancorada nesses contextos. Nesse sentido, tornase fundamental criar oportunidades de reflexão e debate nas quais se possam negociar esses entendimentos, pois, se os sujeitos articulam novos sentidos, apenas o fazem quando são chamados para discutir determinada questão e problematizála.

sendo desenvolvido, no ano de 2006, em 4 comunidades da periferia de Belo Horizonte e tem como ponto de partida laboratórios de criação coletiva e discussões conceituais sobre a relação corpo e espaço, ciberespaço e acessibilidade, redes de softwares livres e internet sem fio, participação e produção cultural” (OCUPAR ESPAÇOS, 2006).

Simone Maria Rocha (smarocha@ig.com.br) é Mestre em Sociologia da Cultura pela Universidade Federal de Minas Gerais (UFMG), Doutora em Comunicação e Cultura pela Universidade Federal do Rio de Janeiro (UFRJ) e Professora Adjunta e pesquisadora do Grupo de Pesquisa em Mídia e Esfera Pública na área de Comunicação e Política do Programa de Pós-Graduação em Comunicação Social da Universidade Federal de Minas Gerais (UFMG).

\section{REFERÊNCIAS BIBLIOGRÁFICAS}

ALVITO, M. 2003. Um bicho-de-sete-cabeças. In : ZALUAR, A. \& ALVITO, M. (orgs.). Um século de favela. Rio de Janeiro : Fundação Getúlio Vargas.
BLUMLER, J. \& GUREVITCH, M. 2000. Rethinking the Study of Political Communication. In : CURRAM, J. \& GUREVITCH, M. (eds.). Mass Media and Society. Oxford : Oxford University. 
DALGHREN，P. \& SPARKS, C. 1993. Communication and Citizenship : Journalism and the Public Sphere in the New Media Age. London : Routledge.

DEMO, P. 2002. O charme da exclusão social. $2^{\mathrm{a}}$ ed. Campinas : Autores Associados.

FOUCAULT, M. 2001. A ordem do discurso. $7^{\mathrm{a}}$ ed. São Paulo : Loyola.

FRASER, N. 1997. From Redistribution to Recognition? Dilemmas of Justice in a Postsocialist Age. In : FRASER, N. Justice Interruptus. New York : Routledge.

HABERMAS, J. 1983-1985. The Tasks of a Critical Theory of Society. In : _ . The Theory of Communicative Action. v. 2. Boston : Beacon Press.

1998. Actions, Speech Acts, Linguistically Mediated Interactions, and the Lifeworld. In : COOKE, M. (ed.). On the Pragmatics of Communication. Cambridge, Mass. : MIT.

HALL, S. 1997. Representation : Cultural Representations and Signifying Practices. London : Sage.

2003. Codificação/decodificação. In : SOVIK, L. (org.). Da diáspora : identidades e mediações culturais. Belo Horizonte: UFMG.

LIVINGSTONE, S. 1998. Making Sense of Television: the Psychology of Audience Interpretation. $2^{\text {nd }}$ ed. New York: Routledge.

LUNT, P. \& LIVINGSTONE, S. 1996. Rethinking the Focus Group in Media and Communication Research. Journal of Communication, v. 46, n. 2, p. 79-98.

MAIA, R. C. M. 2004. Dos dilemas da visibilidade midiática para deliberação política. Disponível em : http://www.unb.br/fac/ comunicacaoepolitica/Rousiley.pdf. Acesso em : 3.nov.2007.

MORGAN, D. 1997. Focus Groups as Qualitative Research. London : Sage.

MOURA, G. 2005. Entrevista concedida via correio eletrônico, em 24.out.

NEUMAN, W. R. 1992. Common Knowledge :
News and the Construction of Political Meaning. Chicago : University of Chicago.

NORRIS, P. 2000. A Virtuous Circle, Political Communication in Postindustrial Societies. Cambridge : Cambridge University.

OLIVEIRA, L. 1997. Os "excluídos" existem? Notas sobre a elaboração de um novo conceito. Revista Brasileira de Ciências Sociais, São Paulo, n. 33.

RINALDI, A. A. 2003. Marginais, delinqüentes e vítimas : um estudo sobre a representação da categoria favelado no tribunal do júri da cidade do Rio de Janeiro. In : ZALUAR, A. \& ALVITO, M. (orgs.). Um século de favela. Rio de Janeiro : Fundação Getúlio Vargas.

ROCHA, S. M. 2005. Favela, soma de exclusões e assimetrias : em busca de uma mobilidade simbólica na cena midiática. Contemporânea, Salvador, v. 3, p. 185-217.

SCHUTZ, A. 1979. Fenomenologia e relações sociais. Organizado por Helmut R. Wagner. Rio de Janeiro : Zahar.

SILVA, J. S. 2004. Identidade, território e práticas culturais : a experiência do Centro de Estudos e Ações Solidárias da Maré - Ceasm. In : HOLLANDA, H. B. (Org.). Cultura e desenvolvimento. Rio de Janeiro : Aeroplano.

THOMPSON, J. B. 1998. A mídia e a modernidade : uma teoria social da mídia. Petrópolis : Vozes.

ZALUAR, A. 1985. A Máquina e a revolta. São Paulo : Brasiliense.

1997. Inclusão e políticas públicas : dilemas teóricos e alternativas políticas. Revista Brasileira de Ciências Sociais, São Paulo, v. 12, n. 35 .

2004. Violência e crime : saídas para os excluídos ou desafios para a democracia. In : . Integração perversa, pobreza e tráfico de drogas. Rio de Janeiro : Fundação Getúlio Vargas.

ZALUAR, A. \& ALVITO, M. 2003. Introdução. In :___. (orgs.). Um século de favela. Rio de Janeiro : Fundação Getúlio Vargas. 


\section{OUTRAS FONTES}

NÓS DO CINEMA. 2006. Disponível em: www.nosdocinema.org.br. Acesso em: 6.abr.2006.

OCUPAR ESPAÇOS. 2006. Apresentação: o espaço como evento. Belo Horizonte : Ocupar Espaços. Disponível em: http:// www.ocupar.org.br. Acesso em: 28.fev. 2007.

VIRTUALBOOKS. s/d. Cidade de Deus - sinopse. Disponível em : http:// virtualbooks.terra.com.br/artigos/ Cidade_de_Deus_Sinopse.htm. Acesso em : 14.maio.2006. 


\section{TELEVISION, LIFE WORLD AND SYMBOLIC MOBILITY: SLUM AND SLUM-DWELLERS FROM TEENAGERS' POINTS OF VIEW}

\section{Simone Maria Rocha}

This article discusses the concept of life world, relating it to the hypothesis of symbolic mobility flowing from analysis of reception and discussion of the television series "City of Men" (Cidade dos Homens", Rede Globo, 2002) carried out through focal groups with youth, slum-dwellers and nonslum dwellers in Belo Horizonte and Rio de Janeiro. We not only consider focal groups as a qualitative research methodology, but as a form of mediation that is capable of stimulating the production of meaning in situations of collective reception, fomenting processes in which representations are questioned and identities are formed and sustained. It is our hypothesis that although representations exhibited by communications media tend to reproduce stereotypes, we can still identify a relative plurality and identify productions that possess an explicit intention to alter such stereotypes. In this regard, communications media provide an important mediation whose ability to filter, "mediatize" and emphasize certain topics offers perspectives, molds images and incites the creation of political and social contexts of debate and interaction. Given the significant presence of communications media in social life, our proposal is to show how televsion and its messages, which play such a fundamental role in cristalizing a stock of knowledge, may also contribute to problematizing and dislocating previously formulated understandings

KEYWORDS: life world; symbolic mobility; television; teenagers; slums. 


\section{TÉLÉVISION, MONDE DE LA VIE ET MOBILITÉ SYMBOLIQUE: LA FAVELA ET SES HABITANTS DANS LA PERSPECTIVE DES ADOLESCENTS}

\section{Simone Maria Rocha}

L'objectif de cet article est de discuter du concept de monde de la vie en le mettant en rapport avec l'hypothèse de la mobilité symbolique et en s'appuyant sur une analyse de la réception et de la discussion de la série télévisée Cidade dos Homens (Cité des Hommes) de la chaîne Globo, 2002. Cette émission se passait auprès de groupes focaux d'adolescents, habitants et non habitants de favela à Belo Horizonte et à Rio de Janeiro. Nous considérons les groupes focaux non seulement comme une méthodologie qualitative de recherche, mais aussi comme une médiation capable de stimuler la production de sens dans des situations de réception collective et de mettre en évidence les processus de mise en question de représentations, de formation et de support d'identité. Bien que les représentations transmises par les moyens de communication reflètent une tendance à la reproduction de stéréotypes, notre hypothèse est que nous pouvons quand même vérifier une relative pluralité dans cet environnement et identifier les productions ayant explicitement l'intention de modifier ces stéréotypes. Les moyens de communication représenteraient donc une importante médiation dont la capacité à filtrer, à rendre médiatique et à renforcer certains thèmes offre des perspectives, modèle les images et incite à la création de contextes politiques et sociaux d'interaction et débat. Vu la présence importante des moyens de communication dans la vie sociale, nous avons pour but de montrer comment la télévision et ses messages qui contribuent énormément à la sédimentation d'un stock de connaissance, contribuent aussi à la mise en question et au déplacement d'entendements préalablement formulés.

MOTS-CLÉS: monde de la vie; mobilité symbolique; télévision; adolescents; favela. 